\title{
Os professores de geografia das escolas públicas do Gama-DF frente ao processo de formação continuada: uma leitura analítica dos anos 2017 e 2018
}

\author{
The teachers of geography of the public schools of Gama-DF facing the \\ process of continued training: an analytical reading of the years 2017 and \\ 2018
}

\author{
Maciel Pereira da Silva'; Cristina Maria Costa Leite ${ }^{\mathrm{II}}$; Jean Volnei Fernandes ${ }^{\mathrm{III}}$
}

\section{RESUMO}

Este artigo decorre de investigação, desenvolvida ao longo dos anos de 2017 e 2018, a respeito do olhar dos docentes de Geografia das escolas públicas do Gama-DF e suas participações no processo de formação continuada, bem como das políticas de fomento, desenvolvidas pela Secretaria de Estado de Educação do Distrito Federal (SEEDF), em relação ao referido processo. Inferimos que o professor, ao longo da vida profissional, deveria ter oportunidades regulares de participar de cursos de formação continuada. Estes teriam por fim revisitar conceitos, reelaborar teorias, refletir acerca de sua prática e do contexto escolar. Assim, no intuito de evidenciar a problematização deste trabalho, indagamos: a SEEDF oferece cursos de formação continuada em Geografia? O professor de Geografia participa de cursos de formação continuada? No olhar do professor de Geografia, os cursos oferecidos contribuem para o aperfeiçoamento da sua prática diária? Utilizou-se a pesquisa qualiquantitativa com a aplicação de questionários semiabertos. Foram pesquisados vinte professores de quatro escolas públicas do Gama-DF, no decorrer dos anos de 2017 e 2018. Os docentes demonstram interesse e consideram importante a participação nos cursos de formação continuada, porém, eles alegam que a política da SEEDF relacionada à promoção e ao incentivo à participação nessa modadalidade de curso não é satisfatória.

Palavras-chave: Formação continuada; Professores de Geografia; Prática; Teoria

\section{ABSTRACT}

This article stems from an investigation, carried out over the years 2017 and 2018, regarding the views of the Geography teachers of the Gama-DF's public schools and their participations in the continuing education course process, as well as the fomentation politics developed by Secretary of State for Education of the Federal District (SEEDF), in relation to said process. We infer that the teacher, throughout his / her professional life, should have regular opportunities to attend continuing education courses. These would have like goal revisit concepts, re-elaborate theories, reflect on their practice and school context. Thus, in the sense of evidencing the problematization of this work, we ask: does SEEDF offer continuing education courses in Geography? Does the Geography teacher take part in continuing education courses? In the eyes of the Geography teacher, do the offered courses contribute to the improvement of your daily practice? Qualiquantitative research was used with the application of semi-open questionnaires. Twenty teachers, from four Gama-DF's public schools, were surveyed during the years 2017 and 2018. Teachers are interested in and consider it important to participate in continuing education courses, however, they argue that SEEDF's politics on promoting and encouraging participation in this type of course is not satisfactory.

Keywords: Continuing Formation; Geography's teacher; Practice; Theory

IDepartamento de Geografia UNB - Doutorando no Programa de Pós-Graduação em Geografia. E-mail: maciel0510@gmail.com ORCID: https://orcid.org/0000-0001-5804-2359

II Departamento de Geografia UnB -Professora do Programa de Pós-Graduação em Geografia. E-mail: criscostaleite@gmail.com ORCID: https://orcid.org/0000-0002-9424-5935

III Departamento de Geografia UnB - Doutorando no Programa de Pós-Graduação em Geografia. E-mail: j.volnei@uol.com.br ORCID: https://orcid.org/0000-0003-1906-1535 


\section{INTRODUÇÃO}

Os cursos de licenciatura têm sofrido um rebaixamento entre a preferência dos jovens ingressantes no ensino superior. Dados de um estudo do Banco Interamericano de Desenvolvimento (BID) (2018) apontaram para um quantitativo de apenas $5 \%$ de jovens do ensino médio possuir interesse pela carreira do magistério (BID, 2018). Alguns elementos são trazidos à baila para justificar esse desprestígio direcionado à docência. Dentre as justificativas, destacamos a presumida ausência de valorização da carreira: o salário médio do professor no Brasil equivale a $49 \%$ da remuneração paga a outros profissionais com qualificação profissional correspondente (BID, 2018); a indisciplina em sala de aula, a superlotação das salas corroboram com essa situação. Do quantitativo de ingressantes nos cursos de licenciatura, muitos afirmam que optaram pelos mesmos por ser uma alternativa, caso não consigam outro emprego, por serem também mais acessíveis e muitas vezes por serem os únicos cursos ofertados em uma Universidade perto de casa (BID, 2018).

Para além da problemática da desvalorização profissional e do ingresso na universidade, há que se observar o fosso existente entre a academia e as escolas do Ensino Fundamental (PIMENTA, 1997). Os egressos da licenciatura, quando confrontados com a realidade educacional nas salas de aula brasileiras, sentem-se desestimulados, perdidos em um contexto para o qual a universidade não os preparou. Diversos autores, dentre eles Cunha (2010), Pimenta (1997), Pires (2012), apontam, em suas pesquisas sobre a formação inicial de professores, que existe um distanciamento entre a academia e a escola, ou melhor, entre o processo de formação acadêmica dos docentes e a realidade nas salas de aula.

Predomina, nos currículos universitários, uma visão dicotômica e equivocada entre teoria e prática, pois há uma concepção utilitarista na qual supõe-se que tudo o que se aprende na universidade está qualificando o estudante para o ingresso na docência. Dito de outra forma, concebe-se que ao frequentar as aulas na universidade, o discente adquire a teoria que, em seguida, será aplicada na sala de aula. Essa é uma visão linear na qual a teoria encontra-se sobreposta à prática. Essa prática, herdada dos princípios positivistas, é apontada como uma mazela curricular. Nessa linha de raciocínio, Cunha (2010), afirma que: 
Ao examinar-se a lógica tradicional dos currículos universitários, se percebe que, muitas vezes, a prática é colocada no ápice dos cursos, geralmente em forma de estágios, dificultando a ação de tomá-la como ponto de partida da teoria. Nesse sentido, essa lógica impede que o ensino assuma os princípios da pesquisa como referente. $O$ estudante não faz a leitura da prática como ponto de partida para a construção da dúvida epistemológica. A prática, nessa lógica de currículo, não é referência para a teoria, ao contrário, como a lógica positivista determina, a teoria é a referência para a prática que deve, fundamentalmente, reproduzi-la em situações concretas (CUNHA, 2010, p.137).

O que se almeja para a superação da dicotomia apontada é que prática e teoria se amalgamem, num esforço pela superação da subordinação de uma à outra. Ambas precisam influenciar-se. Os currículos de formação devem possibilitar aos formandos a possibilidade de vivenciar a realidade da sala de aula. Tal experiência se desenvolveria no curso da graduação.

Por se caracterizar um processo contínuo em sua formação, as dificuldades tornar-se-iam desafios a serem vencidos. Tal atitude viabilizaria ao discente aliar a teoria apreendida na sala de aula à prática desenvolvida no ambiente escolar. Quiçá reconstruir sua teoria inicial embasada nas experiências vivenciadas. Portanto, a prática deve ser vista como um cenário gerador de novas teorias.

Nesse sentido, defendemos a seguinte ideia: a formação continuada deve ser vista como elemento central no processo formativo do professor. Ao se deparar com a realidade escolar, em sua prática diária, ele terá sempre a oportunidade de revisitar as teorias que embasaram a sua prática atual e, então, reformulá-las. Dito de outra forma, a prática, enquanto ação reflexiva, torna-se elemento de transformação da teoria que a rege. Uma e outra estão sujeitas às mudanças (LUCARELLI, 2009).

Entretanto, para que tal ocorra, faz-se mister a dotação de equipamentos básicos e necessários a uma formação continuada. Estes, em tese, devem ser ofertados pelos órgãos empregadores ou mesmo por órgãos particulares, desde que aos mencionados equipamentos tivessem acesso os profissionais da educação. Assim, independentemente de seu tempo de atuação docente, o professor estaria sempre reformulando, atualizando, contextualizando suas teorias, de acordo com sua prática diária. Entende-se, inclusive, que esta seria uma forma de minimizar a problemática relativa à dicotomia entre a teoria e a prática produzida pelos currículos tradicionais de ensino, nos quais a prática é considerada como a aplicação da teoria.

Desta feita, alinhados à ideia alhures exposta, nos propusemos a investigar a elaboração representacional dos docentes de Geografia das escolas públicas do 
Gama, cidade do Distrito Federal (DF), e sua participação no processo de formação continuada, no âmbito da SEEDF, bem como a política de fomento, desenvolvida por esta Secretaria de Educação, em relação ao respectivo processo. Tal estudo foi materializado por meio de produção de dados empíricos no decorrer dos anos de 2017 e 2018 e se sustenta na busca por elucidar as seguintes questões: a SEEDF oferece cursos de formação continuada em Geografia? Houve inovação nos cursos de formação continuada para professores de Geografia oferecidos pela SEEDF do ano de 2017 para o ano de 2018? O professor de Geografia participa de cursos de formação continuada? Houve alteração no quantitativo de professores participantes nos cursos de formação continuada nos anos de 2017 e 2018? No olhar do professor de Geografia, os cursos de formação continuada contribuem para o aperfeiçoamento da sua prática diária? Qual a sua relevância?

Exposta a problemática, cabe-nos apresentar a metodologia eleita para sua elucidação. Optamos pelo uso da metodologia qualiquantitativai por meio do método Discurso do Sujeito coletivo, que de acordo com Lefevre e Lefevre (2014).

(...) é uma forma de metodologicamente resgatar e apresentar as representações sociais obtidas de pesquisas empíricas. Nessas, as opiniões ou expressões individuais que apresentam sentidos semelhantes são agrupadas em categorias semânticas gerais, como normalmente se faz quando se trata de perguntas ou questões abertas (LEFEVRE e LEFEVRE, 2014).

Uma vez que os sujeitos são constituídos a partir de um grupo social, estruturados histórica e espacialmente, ao exporem seus sentimentos e opiniões, estes não falam por si só, pois se configuram porta vozes das diferenças e semelhanças presentes no grupo social ao qual pertencem (SILVA, 2012).

Os instrumentos de pesquisa utilizados foram questionários semiabertos. Ao todo foram aplicados 20 questionários, divididos igualmente nos anos de 2017 e 2018, para professores de Geografia, em quatro escolas públicas da Coordenação Regional de Ensino do Gama-DF. Optamos por realizar a pesquisa em escolas que atendem alunos da segunda fase do ensino fundamental, Centros de Ensino Fundamentali, , pelo maior quantitativo de professores de Geografia em regência de classe nessa etapa de ensino. Os docentes selecionados foram aqueles que aceitaram o convite para participar da pesquisa.

No ano de 2017, após contato com o supervisor pedagógico, visitamos duas escolas em horário de coordenação pedagógicaiii dos professores da área de 
humanas. Explicamos o objetivo da pesquisa e convidamos os docentes de Geografia a participarem respondendo o questionário semiaberto. Dez professores aceitaram o convite. No ano de 2018, realizamos o mesmo procedimento em outras duas escolas e obtivemos a participação de outros dez professores. O questionário em questão está detalhado no quadro 1 a seguir.

Quadro 1 - Questionário semiaberto utilizado na pesquisa

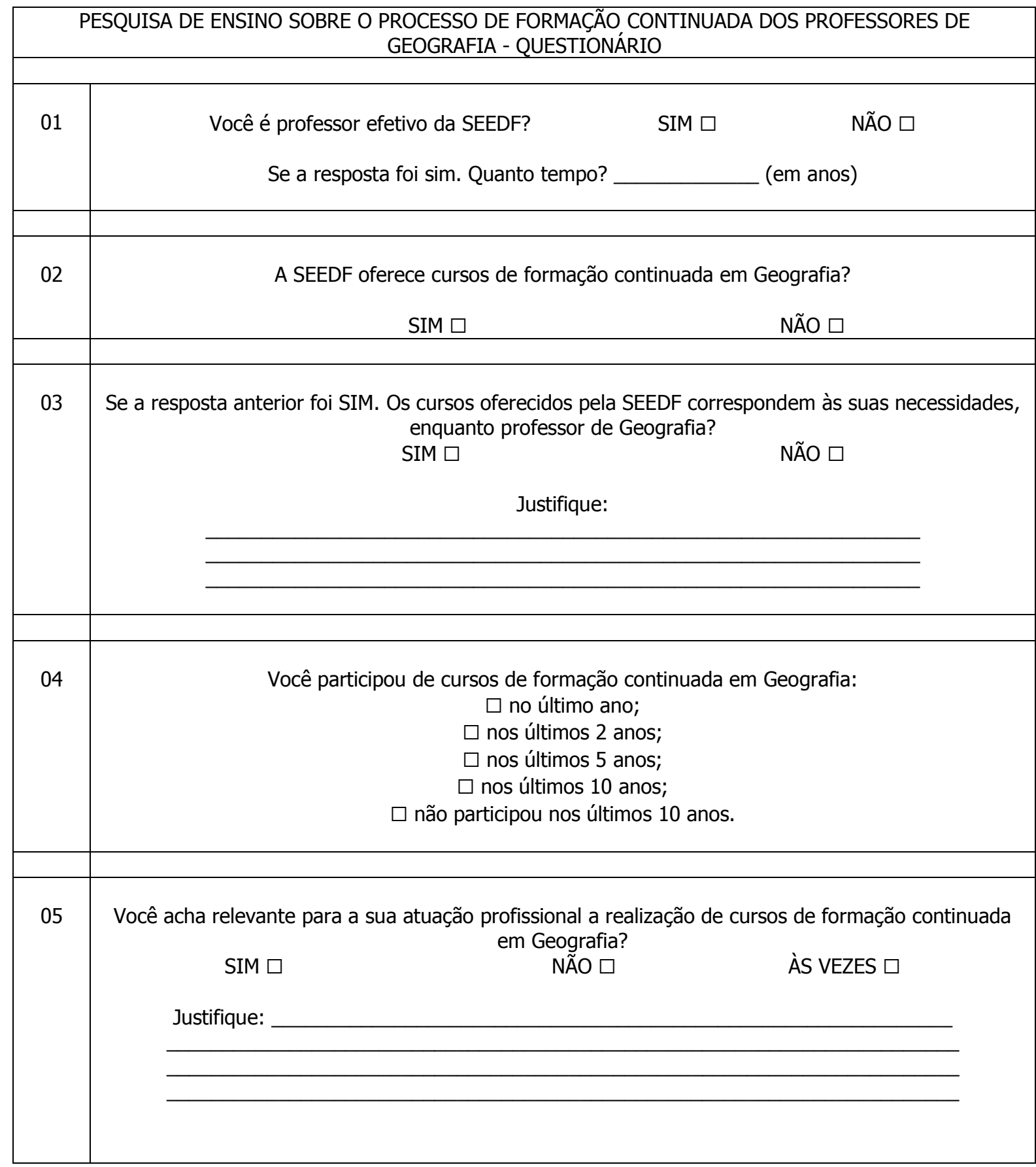

Fonte: Organizado pelos autores. 
O artigo está organizado em duas partes. Na primeira parte do texto, procedemos a análise referente à participação dos professores de Geografia nos cursos de formação continuada, oferecidos pela SEEDF, ao longo dos anos de 2017 e 2018, bem como da política de oferta destes, promovidos pela respectiva Secretaria de Educação. Na segunda parte, analisamos o olhar do professor de Geografia, em relação à importância de se participar de cursos de formação continuada e a contribuição destes em sua prática diária.

\section{A POLÍtICA DA SEEDF PARA O PROCESSO DE FORMAÇÃO CONTINUADA E}

\section{A PARTICIPAÇÃO DOS PROFESSORES DE GEOGRAFIA DAS ESCOLAS DO} GAMA-DF

Encetamos nossa investigação por conhecer o tempo de atuação dos

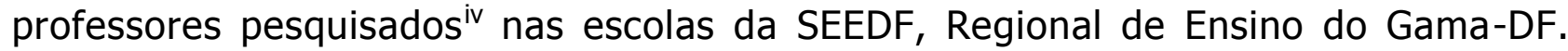
De acordo com os dados dos questionários semiabertos aplicados, eles apresentam situação bastante heterogênea, possuem entre 3 e 29 anos de experiência na atividade docente. No entanto, predominam professores mais experientes. Dos professores consultados, 47\% afirmaram possuir mais de 20 anos de experiência e $41 \%$ estão entre 10 e 20 anos. Somente $12 \%$ destes profissionais possuem menos de 10 anos de atuação docente.

De acordo com Huberman (1995), a carreira docente é marcada por cinco fases distintas: de 1 a 3 anos, denominada entrada na carreira. Nesse período, os aspectos da sobrevivência e da descoberta são vividos paralelamente. A sobrevivência nada mais é do que o encontro do professor com a complexidade do trabalho docente. Nesse momento, ele percebe a distância entre o ideal e o real na sala de aula. A descoberta seria o entusiasmo inicial de se perceber professor e, também, o sentimento de pertença a um grupo de profissionais; a segunda fase ocorre entre 4 a 6 anos, quando o professor se afirma no mercado de trabalho, possui maior segurança, tem melhor domínio de sala e procura definir um estilo próprio de docência; a terceira fase, entre 7 e 25 anos, é marcada pela diversificação, em que o professor apresenta um maior dinamismo no seu fazer 
docente. Nesse momento, o professor encontra-se na fase de consolidação de um repertório pedagógico; a quarta fase, de 26 a 35 anos, é de seriedade e distanciamento afetivo, caracterizada pela maturidade, em que a preocupação com a avaliação externa diminui; a quinta e última fase ocorre com mais de 35 anos. Chamada de conservadorismo ou desinvestimento, o professor apresenta maior resistência a inovações e apego às lembranças do que já passou.

Ao considerar a divisão da carreira docente definida pelo pesquisador, observa-se que $88 \%$ dos docentes pesquisados encontram-se na terceira etapa de suas carreiras. Assim, de acordo com as definições de Huberman (1995), o grupo de professores pesquisados é composto por profissionais experientes, que apresentam um maior dinamismo no seu fazer docente e um repertório pedagógico consolidado.

Infere-se, pela fase da carreira em que se encontram e pelas contribuições analíticas de Huberman (1995), que este grupo de professores esteja disposto a investir em um processo de formação continuada. Este seria um mecanismo de fomento ao dinamismo apresentado em sala de aula e, também, de contribuição com os profissionais mais jovens, ao socializarem suas experiências docentes, advindas de seus repertórios pedagógicos consolidados. Vejamos a figura 1 a seguir, que trata da participação dos sujeitos da pesquisa em cursos de formação continuada nos últimos dez anos.

Os dados obtidos em campo e apresentados na figura 1 corroboram para a inferência de que os professores participam de cursos de capacitação profissional. Segundo observamos na resposta de nossos colaboradores, a maior parte do grupo de professores participou de cursos de formação continuada nos últimos anos. Ao considerar os que participaram no último ano, eles correspondem a $50 \%$. Este percentual se eleva para $70 \%$ do grupo pesquisado, ao analisarmos os últimos dois anos. No entanto, em situação oposta, encontram-se $5 \%$ dos docentes, que afirmam ter realizado curso de formação continuada somente nos últimos dez anos e outros $10 \%$ que não participaram desse tipo de atividade no período mencionadov .

Prosseguimos, também, a uma comparação a respeito da participação dos sujeitos dessa pesquisa em cursos de formação continuada nos anos de 2017 e 2018. Os dados estão representados na figura 2, a seguir. 
8 | Os professores de geografia das escolas públicas do Gama - DF frente ao processo de formação continuada: uma leitura analítica dos anos 2017 e 2018

Figura 1 - A participação dos professores de Geografia da rede pública de ensino do Gama-DF em cursos de formação continuada nos últimos 10 anos - (\%).

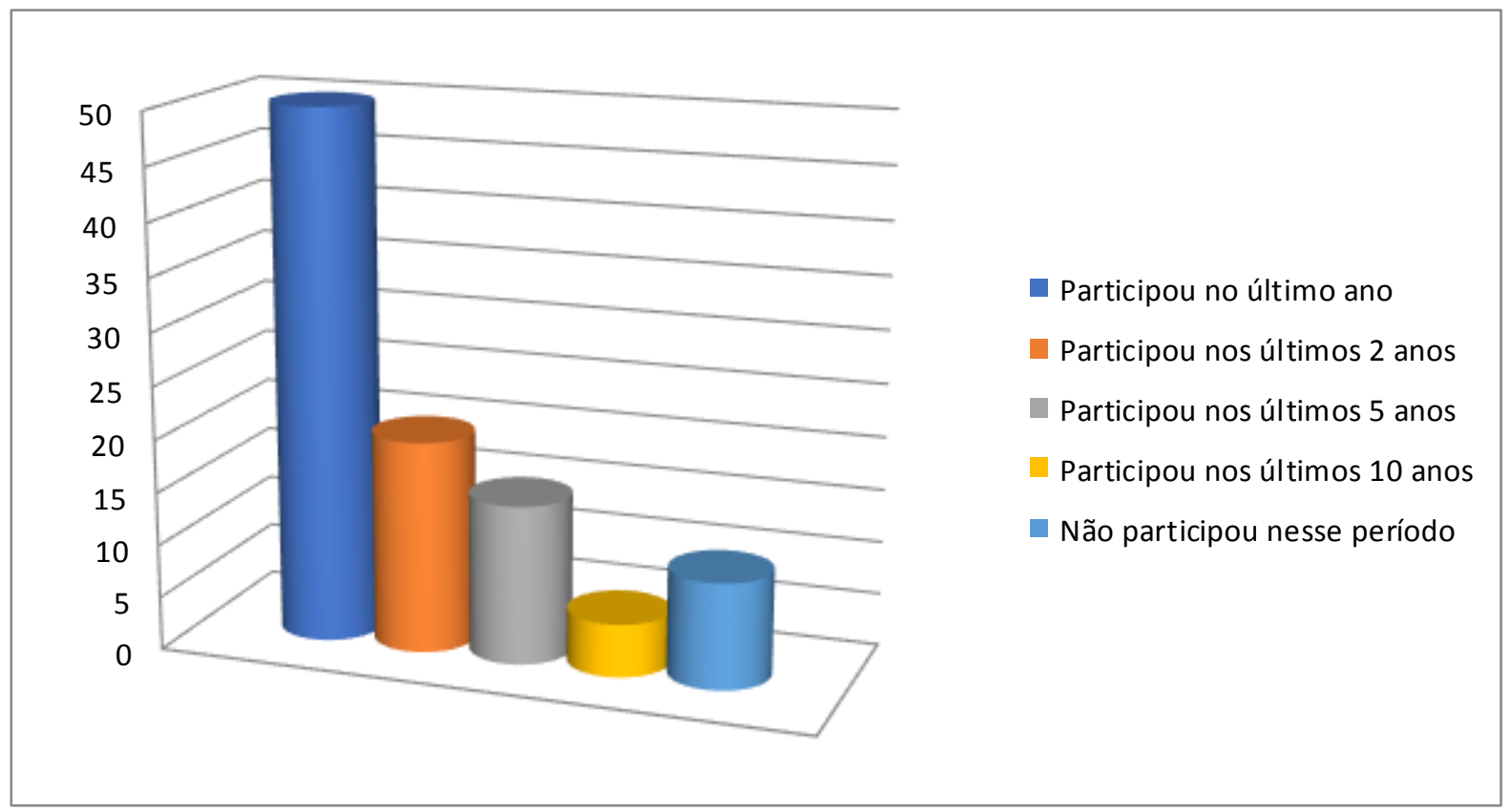

Fonte: Organizado pelos autores.

Nota: Dados produzidos a partir dos questionários semiabertos aplicados pelos autores a professores de Geografia em escolas públicas da Regional de Ensino do Gama-DF nos anos de 2017 e 2018.

Figura 2 - A participação dos professores de Geografia da rede pública de ensino do Gama-DF em cursos de formação continuada nos últimos 10 anos. Situação em 2017 e $2018-(\%)$

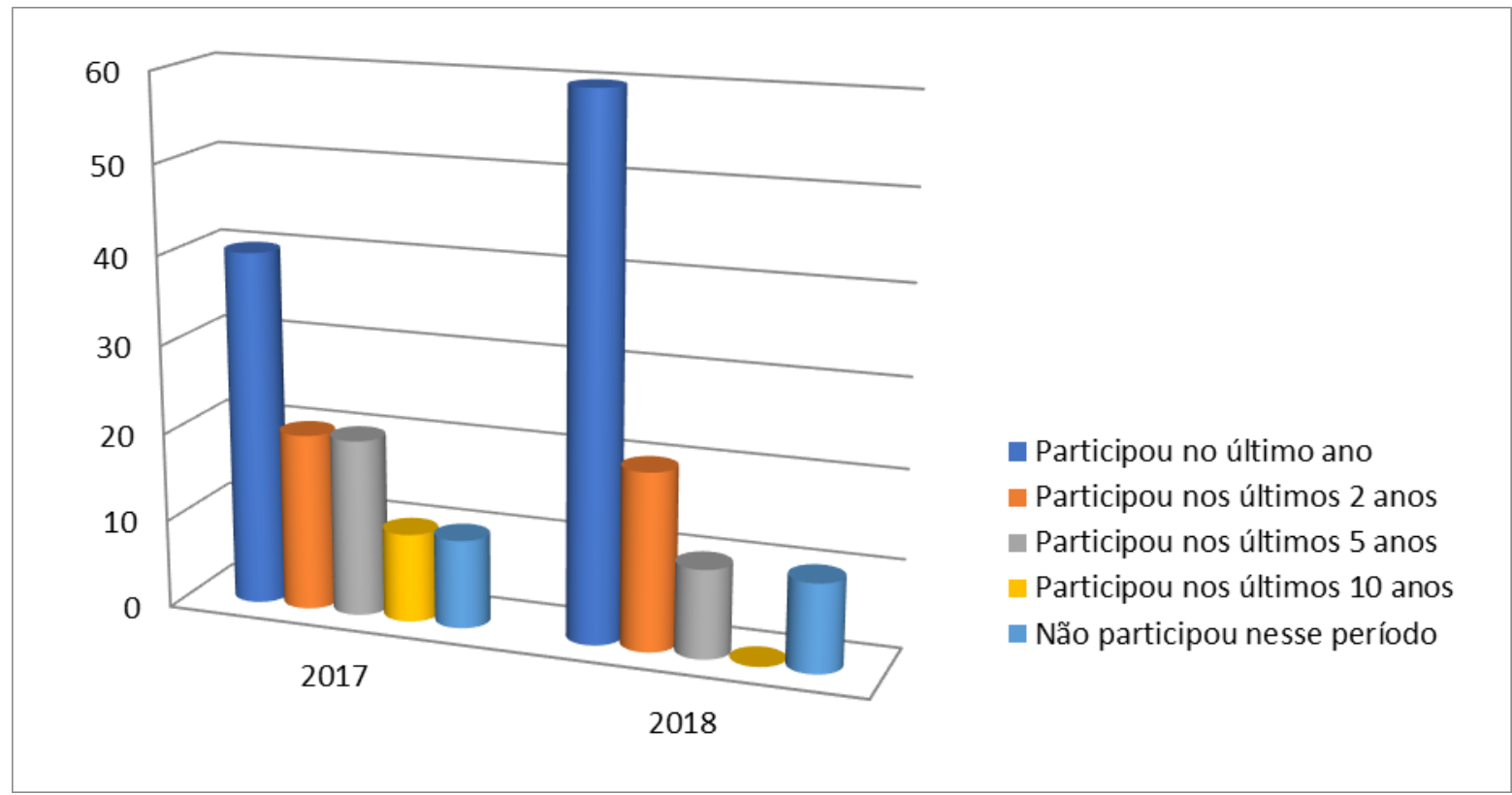

Fonte: Organizado pelos autores.

Nota: O gráfico representa a participação dos professores de Geografia da rede pública de ensino do Gama-DF em curso de formação continuada nos últimos dez anos. Situação em 2017 e 2018. Dados 
produzidos a partir dos questionários semiabertos aplicados pelos autores a professores de Geografia em escolas públicas da Regional de Ensino do Gama-DF nos anos de 2017 e 2018.

Os dados da figura 2 nos permitem concluir que o número de professores de Geografia da rede pública de ensino do Gama, participantes de cursos de formação continuada no último ano, foi maior em 2018, com $60 \%$ de participação, em comparação ao ano de 2017 , em que $40 \%$ dos docentes participaram de cursos dessa modalidade. Assim, reduziu-se, também, o número de participantes nos últimos cinco anos: de $20 \%$ para $10 \%$, bem como aqueles que participaram nos últimos dez anos: de $10 \%$ para $00 \%$.

Inferimos que o aumento da participação dos docentes nos cursos de formação continuada no ano de 2018 em relação ao ano de 2017 possa ter ocorrido em função da necessidade desses diplomas para o avanço na carreira do magistério público do Distrito Federal. A Lei no 5.105, de 03 de maio de 2013, que normatiza a respectiva carreira profissional, em seu artigo 15, traz a seguinte redação:

Art. 15. São requisitos essenciais para a concessão da progressão vertical:a) encontrar-se em efetivo exercício;b) cumprir, a cada cinco anos de efetivo exercício, o disposto no art. 14, § $1^{0}$, II, acompanhado de certificado de cursos na área de atuação, totalizando carga horária de cento e oitenta horas-aula, conforme norma editada pela Secretaria de Estado de Educação (DISTRITO FEDERAL, 2013, p. 2/3).

De acordo com a referida Lei, portanto, o professor deve apresentar certificados que totalizem pelo menos cento e oitenta horas aulas de participação em cursos de formação continuada a cada cinco anos de trabalho, sob pena de estagnarse na carreira.

Outra possível explicação para o aumento na participação dos professores de Geografia das escolas públicas do Gama em cursos de formação continuada pode estar relacionado ao aumento da oferta destes cursos pela Escola de Aperfeiçoamento dos Profissionais da Educação (EAPE) vi, no respectivo período. Procedemos, junto ao respectivo órgão, a um levantamento dos cursos relacionados ao ensino de Geografia oferecido nos anos de 2017 e 2018. O resultado está apresentado no quadro 2 a seguir.

De acordo com os dados do quadro 2, então, nota-se o aumento da oferta de cursos em temáticas relacionadas à Geografia do ano de 2017 para o ano 2018. Este pode ser, conforme mencionamos alhures, um fator de contribuição para o aumento da presença dos sujeitos desta pesquisa em cursos de formação continuada. 
Quadro 2 - Cursos relacionados ao ensino de Geografia, oferecidos pela EAPE nos anos de 2017 e 2018

\begin{tabular}{|c|c|}
\hline 2017 & 2018 \\
\hline $\begin{array}{l}\text { Uso do Software Google Earth Pro como recurso } \\
\text { didático para a Análise Ambiental e no Ensino da } \\
\text { Geografia: } 90 \text { horas aula }\end{array}$ & $\begin{array}{l}\text { Formação de professores de Geografia de } 6^{\circ} \text { e } 70 \text { ano do ensino } \\
\text { fundamental na temática "mobilidade de trânsito". } \\
120 \text { horas aula }\end{array}$ \\
\hline $\begin{array}{l}\text { Distrito Federal: seu povo, sua história: } 180 \text { horas } \\
\text { aula }\end{array}$ & Distrito Federal: seu povo, sua história:180 horas aula \\
\hline \multirow[t]{5}{*}{$\begin{array}{l}\text { Curso de formação de professores(as) do } 4^{\circ} \text { ano do } \\
\text { ensino fundamental e professores(as) do } 1^{0} \\
\text { segmento da educação de jovens e adultos na } \\
\text { temática "mobilidade e trânsito": } 120 \text { horas aula }\end{array}$} & $\begin{array}{l}\text { Formação de professores de Geografia do segundo segmento } \\
\text { de jovens e adultos na temática "mobilidade de trânsito": } 120 \\
\text { horas aula }\end{array}$ \\
\hline & $\begin{array}{l}\text { Biogeografia aplicada à conservação da biodiversidade e análise } \\
\text { ambiental: } 40 \text { horas aula }\end{array}$ \\
\hline & Trilhas ecopedagógicas no Bioma Cerrado. 60 horas aula \\
\hline & $\begin{array}{c}\text { Aplicação da Educação Ambiental na Fundação Jardim Zoológico } \\
\text { de Brasília. } \\
40 \text { horas aula }\end{array}$ \\
\hline & $\begin{array}{l}\text { Reconhecendo meu território, descobrindo possibilidades. } \\
48 \text { horas aula. }\end{array}$ \\
\hline
\end{tabular}

Fonte: Organizado pelos autores. http://www.se.df.gov.br. Acesso em: 22/10/2018.

Há, ainda, outros elementos que podem funcionar como estímulo à participação dos docentes em Geografia nos cursos de aperfeiçoamento profissional. Dentre eles, o direito de afastar-se temporariamente do trabalho para realizar cursos de pós-graduação stricto-sensu. A Lei no 5.105, de 03 de maio de 2013, artigo 12, § 30, estabelece:

Fica garantido, anualmente, o afastamento remunerado de, no mínimo, um por cento dos servidores ativos para a realização de cursos de mestrado ou de doutorado, a título de formação continuada, respeitados os critérios de conveniência e oportunidade da Administração, garantida a remuneração do cargo, percebida no ato do afastamento, conforme norma editada pela Secretaria de Estado de Educação (DISTRITO FEDERAL, 2013, p. 2).

Embora a respectiva Lei e, consequentemente, o direito de licenciar-se para participação em cursos de mestrado e doutorado esteja em vigor desde o ano de 2013, este não pode deixar de ser visto como um fator de possível influência ao aumento da presença dos professores de Geografia em cursos de formação continuada, conforme detectado por esta pesquisa. 
Conquanto, número considerável dos professores pesquisados confirme a participação em tais eventos nos últimos anos, consideramos pertinentes alguns questionamentos a esse respeito: qual é o nível de qualidade dos cursos em questão? A participação em cursos de formação resulta na alteração, ou não, da prática docente? A participação nos referidos eventos se dá de forma espontânea ou imposta pelo órgão gestor?

Apple (2017), em seu livro intitulado "A educação pode mudar a sociedade?", discute o papel da escola atual na sociedade. Ele aponta que a escola caminha no sentido de perder a sua função social de escola cidadã, formadora de mentes conscientes, sensíveis às questões humanas e comprometidas com a transformação social, como a busca pela igualdade e justiça social. Ao contrário, a escola atual tende a absorver cada vez mais valores mercadológicos. Para o autor:

No status neoliberalista, escolha, competição, mercados nos levarão à terra prometida de escolas eficientes e eficazes. E tais escolas terão um papel fundamental na transformação do público em privado. Esse processo nos levará a uma economia do sonho enquanto reconquistamos nosso ímpeto competitivo no mercado global (APPLE, 2017, p.19).

De acordo com o pesquisador, a qualidade das escolas e dos professores está diretamente relacionada com a preparação dos estudantes para serem aprovados em exames seletivos, para serem competitivos. Nessa perspectiva o ensino é visto como mercadoria. Algumas das transformações preconizadas pelo autor já são constatadas pelas escolas públicas da educação básica. Estas, cada vez mais, têm se preocupado em preparar seus alunos para as avaliações standards em nível nacional e internacional, a exemplo do Índice de Desenvolvimento da Educação básica (IDEB) e do Programa Internacional de Avaliação de Estudantes (PISA). Ademais, em abrir espaço no mercado de trabalho para os alunos egressos. Disciplinas do núcleo de humanas têm perdido espaço para o núcleo de exatas e códigos e linguagens. Inserem-se nos referidos núcleos, respectivamente, Matemática, Português e Ciências. Tais disciplinas são pensadas, no contexto em análise, como determinantes para uma boa classificação nas avaliações mencionadas e para o acesso ao mercado de trabalho.

Inferimos que essa mesma lógica de análise possa ser aplicada a grande parte dos cursos de formação continuada, inclusive aos cursos que os sujeitos dessa pesquisa alegam ter frequentado. Há uma série de empresas privadas no Distrito 
Federal que oferecem esse tipo de formação a professores da educação básica. $\mathrm{Na}$ maioria das vezes são cursos feitos a distância, sem nenhum tipo de tutoria ou qualquer outra orientação docente. A dinâmica consiste em pagar pelo curso, receber as apostilas com os ditos instrumentos de avaliação e, em seguida, ser diplomado. Não queremos afirmar aqui, é evidente, que todos os cursos de formação continuada realizados pelo grupo pesquisado sejam oriundos dessa prática. É apenas uma possibilidade. Sabemos que existe, também, a oferta de outras modalidades de formação.

Já mencionamos em outro momento, nesse mesmo texto, que entendemos a formação continuada como uma oportunidade para o docente em Geografia revisitar e reformular suas velhas teorias, por meio de suas práticas mais recentes. Assim, em tempos de rápidas transformações sociais, a exemplo das primeiras décadas deste século, torna-se imperativo rever as velhas teorias. As práticas, nesse contexto, mudam mais rapidamente, em atendimento às novas realidades sociais.

Para Cunha (2010), a prática docente, em tempos atuais, ganha maior complexidade em função das rápidas e recentes transformações ocorridas na sociedade, especialmente pelas mudanças observadas no mundo laboral, na organização familiar e no desenvolvimento midiático. Ainda, de acordo com a autora, no novo mundo laboral, exigem-se trabalhadores multifuncionais, polivalentes ou flexíveis, para atender à demanda do novo padrão de acumulação: o Toyotismo. A extraordinária massificação dos meios de comunicação e acesso aos conteúdos midiáticos e redes sociais, pós Terceira Revolução Industrial, produziu uma cultura juvenil pautada por valores culturais globais, portanto, muito diversos. As novas organizações nos desenhos familiares fogem ao modelo patriarcal, no qual se fragiliza a autoridade da figura paterna, o que facilita a absorção da cultura midiática global.

Todas essas transformações sociais convergem para os espaços educacionais, tornam-nos mais dinâmicos e complexos e exige maior flexibilidade na ação docente. Para Silva e Oliveira (2016), neste cenário:

Há uma evidente complexificação da condição docente que caminha junto com a precarização de suas condições de trabalho, tendo alterado a autoestima do professor e sua representação social, criando uma tensão identitária. O trabalho do professor se torna bastante complexo em meio a essa nova situação. 0 mundo contemporâneo cria um sujeito diferente daquele de uma década atrás, sujeitos esses (crianças e jovens) que levam para a escola um enorme repertório de valores e símbolos que dão todo um colorido diferente a tal espaço, tornando-o cada vez mais contraditório. Nesses termos, é premente a necessidade de o 
espaço escolar ser debatido nos cursos de formação para que o professor possa ter uma compreensão concreta do processo de produção do espaço da escola. E o docente devidamente preparado tem maiores condições de exercer sua profissão, contribuindo para uma formação cidadã e crítica dos jovens-alunos (SILVA e OLIVEIRA, 2016, p. 63).

Diante dessa realidade, portanto, e alinhados ao posicionamento dos autores, reafirmamos a necessidade de autoformação do professor de Geografia. Urge atualizar-se por meio dos cursos de formação continuada, sob pena de não mais conseguir atender às novas demandas advindas em sua rotina profissional. Ou mesmo de perder-se neste torvelinho de transformações para o qual não se encontra aberto ou preparado.

Outro achado, desta pesquisa, que julgamos merecer análise, refere-se ao quantitativo de professores de Geografia da educação básica nas escolas públicas do Gama-DF, que atuam em regime de contrato temporário de trabalhovii. Eles correspondem a $15 \%$ do grupo pesquisado. Essa modalidade de contrato de trabalho fragiliza o processo de estímulo à participação docente em cursos de formação continuada. Aos profissionais inseridos nessa modalidade de contrato trabalhista não é estendido o direito de afastar-se temporariamente do trabalho para a participação em cursos de mestrado e doutorado, conforme está previsto na Lei que regulamenta o magistério público do DF, já apontada em outro momento neste texto. Ainda, por atuarem nessa modalidade de trabalho, esses profissionais não ascendem na carreira e não recebem, portanto, recompensa salarial por este feito, configurando-se, assim, em um fator de desestímulo.

\section{A FORMAÇÃO CONTINUADA NA SEEDF: O OLHAR DO PROFESSOR DE} GEOGRAFIA DAS ESCOLAS DO GAMA/DF

Prosseguimos, em nossas arguições, ao grupo de professores/colaboradores que afirmaram reconhecer a oferta de cursos de formação continuada pela EAPE. Ainda, por meio dos questionários semiabertos, a eles perguntamos: os cursos oferecidos correspondem às suas necessidades enquanto docente? $35 \%$ disseram que sim e os demais $65 \%$ afirmam não corresponder. Solicitamos aos que concluíram que a oferta não correspondia a suas necessidades ou expectativas que justificassem sua resposta. Seguem algumas das assertivas neste sentido: 
"Os cursos estão sempre distantes da realidade de sala de aula. Fazem extensas abordagens teóricas e poucas vezes apresentam propostas práticas que facilitem realmente o trabalho do professor" (Professor de Geografia efetivo na SEEDF há 14 anos. Questionário semiaberto respondido em 24/11/2017).

"Muitas vezes os cursos oferecidos não são suficientes quanto ao número de vagas e também não é pertinente à área de atuação. O que percebo, também, é que de uns tempos para cá são oferecidos bem menos oportunidades de cursos pela SEEDF' (Professor de Geografia efetivo na SEEDF há 29 anos. Questionário semiaberto respondido em 24/11/2017).

"Nem sempre os cursos estão diretamente relacionados às minhas práticas didáticas pedagógicas" (Professor de Geografia efetivo na SEEDF há 25 anos. Questionário semiaberto respondido em 24/11/2017).

"Normalmente, são cursos genéricos e não focam a área de ensino de Geografia em si" (Professor de Geografia efetivo na SEEDF há 21 anos. Questionário semiaberto respondido em 24/11/2017).

"Geralmente os cursos são para formação geral" (Professor de Geografia efetivo na SEEDF há 04 anos. Questionário semiaberto respondido em 24/09/2018).

"A maioria está associada à História e são sobre Brasília e sua criação, os que deveriam contemplar professores de Geografia estão disponíveis em locais muito distantes e são voltados para áreas de Ciências (pouco abordam conceitos geográficos importantes) são muito técnicos." (Professor de Geografia efetivo na SEEDF há 17 anos. Questionário semiaberto respondido em 24/09/2018).

Uma análise das justificativas apresentadas evidencia o não alinhamento das temáticas dos cursos de formação continuada oferecidos pela EAPE com as reais necessidades dos professores em sala de aula. Inferimos que as necessidades dos professores estejam relacionadas mais ao "como ensinar?"e menos ao "o que ensinar?". Saber o conteúdo não é suficiente. É preciso saber como ensinar esse conteúdo; torná-lo atraente, acessível e útil aos alunos. É preciso transformar o conhecimento que o professor possui dos conteúdos em representações, que favorecem a aprendizagem dos alunos (PONTUSCHKA e LOPES, 2015).

Pontuschka e Lopes (2015) fazem uma análise das metodologias aplicadas ao ensino. Para tal, embasam-se na obra de Lee S. Shulman (2005). Os autores fazem um alerta para a necessidade de uma tradução do conteúdo acadêmico para o 
universo dos alunos. Assim sendo, este se tornaria significativo para os mesmos. E a sua aplicação menos penosa aos docentes. Shulman, no curso de seus estudos, desenvolveu uma categoria de análise que nomeou "conhecimento pedagógico do conteúdo (CPC)". Tal categoria de conhecimento incide sobre a prática profissional docente, inclusive naquela desenvolvida pelos professores de Geografia. Segundo Shulman (2005), os conhecimentos necessários à docência são os seguintes:

- conhecimento do conteúdo a ser ensinado: refere-se ao conhecimento da disciplina na qual o professor é um especialista (geografia, história, matemática etc.);

- conhecimento pedagógico geral: reporta-se, especialmente, àqueles princípios e estratégias gerais de manejo e organização da aula que transcendem o âmbito da disciplina que o professor ministra;

- conhecimento do currículo: trata-se de um especial domínio dos materiais e dos programas que servem como "ferramentas para o ofício" do docente;

- conhecimento pedagógico do conteúdo: refere-se ao especial amálgama entre matéria e pedagogia que constitui uma esfera exclusiva dos professores, sua forma própria e especial de compreensão profissional;

- $\quad$ conhecimento dos alunos e de suas características;

- conhecimento dos contextos educativos: abarca desde o funcionamento do grupo ou da aula, a gestão e o financiamento dos distritos escolares, até o caráter das comunidades e culturas;

- $\quad$ conhecimento dos objetivos, das finalidades e dos valores educativos e de seus fundamentos filosóficos e históricos.

Compreendemos, assim, com base em Shulman (2005), que esses conhecimentos são fundamentais para o ensino de Geografia, com destaque para um conhecimento imprescindível, que é o conhecimento didático do conteúdo de Geografia. O docente precisa saber o conteúdo, mas precisa saber, também, como ensinar. Inferimos, portanto, que os referidos cursos de formação continuada oferecidos pela EAPE não estejam focados na promoção do Conhecimento Pedagógico dos Conteúdos aos professores de Geografia. Daí a não correspondência, presente no relato dos docentes pesquisados, entre as reais necessidades no âmbito da sala de aula e as temáticas dos cursos ofertados. 
No sentido de avançar em nossa investigação científica, perguntamos ainda a nossos professores/colaboradores: você acha relevante para a sua atuação profissional a participação em cursos de formação continuada? Todos os entrevistados, sem nenhuma exceção, responderam que sim. Pedimos para justificarem suas respostas. Obtivemos os seguintes relatos:

"Para que possamos estar a par dos novos pensamentos da Geografia. Atualizar-se quanto ao que ensinar aos alunos que estão no ensino fundamental $e$ médio, porque o que se ensina na universidade é muito distante da realidade escolar" (Professor de Geografia efetivo na SEEDF há 16 anos. Questionário semiaberto respondido em 24/11/2017).

"Porque a realização destes cursos contribui para a interação entre a teoria e a prática, logo é de suma importância para o crescimento profissional do professor" (Professor de Geografia efetivo na SEEDF há 10 anos. Questionário semiaberto respondido em 24/11/2017).

"Reciclar é necessário, pois o cotidiano nosso, em sala de aula, é extenso, não nos dando tempo de conhecer novos conhecimentos pedagógicos" (Professor de Geografia efetivo na SEEDF há 23 anos. Questionário semiaberto respondido em 24/11/2017).

"Sim. Pois dependendo do curso amplia a visão do professor acerca da sala de aula, do público com o qual se trabalha e das novas metodologias de avaliação a serem implementadas no percurso da aprendizagem" (Professor de Geografia efetivo na SEEDF há 3 anos. Questionário semiaberto respondido em 24/11/2017).

"É a melhor forma de atualizar conteúdos, conceitos e aprender novas práticas pedagógicas." (Professor de Geografia efetivo na SEEDF há 17 anos. Questionário semiaberto respondido em 24/09/2018).

"É importante para a Educação que o professor seja pesquisador. Desta forma, os processos de ensino e aprendizagem serão cada vez mais satisfatórios." (Professor de Geografia efetivo na SEEDF há 5 anos. Questionário semiaberto respondido em 24/09/2018)

Nota-se, nos relatos dos professores, expressões como atualizar-se, reciclar, teoria, prática, metodologias de ensino, formas de avaliação, distância entre escola e universidade. Os relatos revelam que os professores possuem necessidades de voltar aos espaços formativos para "ampliar suas visões", ou seja, para se atualizarem dos 
novos estudos a respeito da docência, das metodologias de ensino, das formas de avaliação em Geografia, de como lidar com o aluno do século XXI, que eles se referem como "público com o qual se trabalha". Em suma, eles esperam que a formação continuada possa contribuir para a melhoria de suas práticas diárias, enquanto professores de Geografia, além de a perceberem como uma oportunidade de "interação entre teoria e prática", de acordo com seus próprios dizeres. Pimenta (1997) corrobora a importância dessa modalidade de formação ao afirmar que:

\begin{abstract}
Configurando-se como uma articulação possível entre pesquisa e política de formação, as novas tendências investigativas sobre formação de professores valorizam o que denominam o professor reflexivo (Schón, 1990; Alarcão, 1996). Opondo-se à racionalidade técnica que marcou o trabalho e a formação de professores, entende-o como um intelectual em processo contínuo de formação. Enquanto tal, pensar sua formação significa pensá-la como um continuum de formação inicial e contínua. Entende, também, que a formação é, na verdade, auto formação, uma vez que os professores reelaboram os saberes iniciais em confronto com suas experiências práticas, cotidianamente vivenciadas nos contextos escolares. É nesse confronto e num processo coletivo de troca de experiências e práticas que os professores vão constituindo seus saberes como praticum, ou seja, aquele que constantemente reflete na e sobre a prática (PIMENTA, 1997).
\end{abstract}

De acordo com a autora, o processo de formação não se encerra na formação inicial. Ele é um processo contínuo. Após o mesmo, quando volta aos espaços de formação, o professor encontra-se tocado, de certa forma, transformado. Ele já possui vivências e experiências, advindas de sua prática diária. Essas experiências irão servir de base às suas reflexões e, certamente, novas propostas de ação, diferentes das anteriores, serão formuladas. Inferimos, com base nas narrativas dos professores, que este seja seus posicionamentos a respeito da formação continuada. Eles percebem a necessidade, valorizam e se interessam por realizá-las ao longo de sua atuação profissional.

Embora esta pesquisa tenha revelado que existem políticas de estímulo, por parte da SEEDF, para que o professor invista no processo de sua formação continuada, nota-se que as oportunidades oferecidas pela instituição ainda são limitadas. Elas não correspondem às reais necessidades dos professores e não atendem, satisfatoriamente, aos profissionais desta disciplina. É preciso avançar, no sentido de ofertar cursos que tenham relação direta com a prática em Geografia e que atendam a todos os docentes em Geografia na respectiva Secretaria de Educação. 


\section{CONSIDERAÇÕES FINAIS}

Os estudos bibliográficos relacionados ao assunto proposto nos permitiram a apropriação dos conceitos de teoria e prática. Percebemos que são componentes de um mesmo processo, indissociáveis. A prática possui potencial para a reformulação da teoria. Daí defendermos a ideia que aos professores de Geografia das escolas públicas do Gama-DF - e também aos demais professores - deve ser possibilitada a participação contínua em cursos de formação. Assim, eles teriam a oportunidade de revisitar suas teorias e, possivelmente, reformulá-las.

No decorrer da pesquisa foi possível perceber que a SEEDF, por meio do plano de Carreira do Magistério Público do Distrito Federal, possui políticas de estímulo ao processo de formação continuada de seus professores. Dentre elas, a política de Afastamento Remunerado para Estudos e a progressão vertical na carreira mediante a apresentação de certificados de cursos de aperfeiçoamento. No entanto, as medidas ainda são insuficientes. Urge por aperfeiçoamento. A EAPE, por exemplo, oferece poucos cursos de formação nas temáticas relacionadas ao ensino de Geografia, embora tenha sido detectado, por meio deste estudo, o aumento da oferta destes do ano de 2017 para o ano de 2018.

No que se refere ao olhar do professor de Geografia, em relação aos cursos de formação continuada, conclui-se que são representados de forma positiva. Os docentes reconhecem a necessidade da participação nesse tipo de curso ao longo de suas carreiras. No entanto, apresentam críticas quanto à qualidade dos cursos oferecidos. Afirmam, majoritariamente, que os cursos não estão alinhados as suas reais necessidades em sala de aula.

As transformações tecnológicas do final do século XX e início do século XXI trouxeram uma série de mudanças para a sociedade contemporânea. Tais mudanças convergem, por meio das culturas juvenis, para os espaços educacionais e complexifica-os. Ampliam, assim, as dificuldades diárias dos professores. Daí o maior interesse do grupo por temáticas voltadas para o modo de se relacionar com os alunos, ou seja, temáticas relacionadas aos Conhecimentos Pedagógicos dos Conteúdos, o que, certamente, poderia ajudar o professor a enfrentar os desafios impostos pela atual realidade escolar. 


\section{REFERÊNCIAS}

APPLE, M. W. A educação pode mudar a sociedade? Petrópolis: vozes, 2017

BID. BANCO INTERAMERICANO DE DESENVOLVIMENTO. Profissão: professor na América Latina: Por que a docência perdeu prestígio e como recuperá-lo? Washington, D. C.: Banco Interamericano de Desenvolvimento, 2018.

CUNHA, M.I. Lugares de formação: tensões entre a academia e o trabalho docente. In: DALBEN, A.I.L.F et al. (Orgs.). Convergências e tensões no campo da formação e do trabalho docente. Belo Horizonte: Autêntica, 2010. p.129-149.

DISTRITO FEDERAL. Lei no 5.105, de 03 de maio de 2013. Reestrutura a Carreira Magistério Público do Distrito Federal. Brasília: Diário Oficial do Distrito Federal, 2013, p. $1-7$.

HUBERMAN, M., O ciclo de vida profissional dos professores. In: NÓVOA, A. Vidas de professores. 2. ed. Portugal: Porto Editora, 1995.

LEFEVRE, F.; LEFEVRE, A. M. C. Discurso do sujeito coletivo: representações sociais e intervenções comunicativas. Texto Contexto Enferm: Florianópolis, p. 502-507, abr.jun., 2014.

LUCARELLI, E. Teoria y práctica en la universidad. La innovación en las aulas. Buenos Aires: Editora Mino e Dávilla, 2009.

PIMENTA, S. G. Formação de professores: saberes da docência e identidade do professor. Nuances. São Paulo, vol. III, p. 5-14,1997.

PIRES, L. M. Da formação inicial ao exercício da profissão docente: entre desafios, perspectivas e práticas no cotidiano do professor de Geografia. Revista Brasileira de Educação Geográfica, Campinas, v. 2, n. 4, p. 15-39, jul./dez., 2012.

PONTUSCHKA, N. N.; LOPES, C. S. O conhecimento pedagógico do conteúdo na prática profissional de professores de geografia. GEOUSP - Espaço e Tempo, São Paulo, v. 19, n. 1, p. 76-92, 2015.

PONTUSCHKA, N. N et al. Para ensinar e aprender Geografia. São Paulo: Cortez, 2007.

SHULMAN, L. S. Conocimiento y enseñanza: fundamentos de la nueva reforma. Profesorado. Revista de Currículum y Formación de Profesorado. Granada, España, v.9, n.2, p.1-30, 2005.

SILVA, A. B.; OLIVEIRA, S. R. L. Docência em Geografia: alguns elementos acerca do processo de formação. In: ALVES, A. O.; KHAOULE, A. M. K. (Orgs). A Geografia no cenário das políticas públicas educacionais. Goiânia: Alfa, 2017. p. 57-72.

SILVA, G. E. R. Valparaíso de Goiás-GO: migração e dinâmica socioespacial 1995/2010. 2012. 196 p. Dissertação (Mestrado em Geografia) - Universidade Federal de Goiás, Goiânia. 
' Cf. LEFEVRE, Fernando e LEFEVRE, Ana Maria Cavalcanti. Discurso do Sujeito Coletivo: representações sociais e intervenções comunicativas. In: Texto Contexto Enfermagem: Florianópolis, abr-jun; 2014; pág. 502-507.

ii Na rede pública de ensino do Distrito Federal as escolas são classificadas da seguinte forma: Escola Classe (EC), que atende a alunos das séries iniciais do ensino fundamental; Centro de Ensino Fundamental (CEF), com alunos das séries finais do ensino fundamental; Centro de Ensino Médio (CEM), alunos do ensino médio e Centro Educacional (Ced), que atende tanto a alunos do ensino fundamental, séries iniciais ou finais, quanto a alunos do ensino médio.

iii De acordo com a Lei no 5.105 de 03 de maio de 2013, que reestrutura a Carreira Magistério Público do DF, o professor de educação básica submetido ao regime de quarenta horas semanais faz jus a dez horas de coordenação pedagógica, que deve ser realizada na escola em turno contrário ao turno de regência, em três dias da semana.

iv Por uma questão de recorte estabelecido para esta pesquisa, este dado se refere somente aos professores efetivos da SEEDF.

${ }^{\vee}$ De acordo com a Lei no 5.105, de 03 de maio de 2013, que reestrutura a carreira Magistério Público do Distrito Federal, o docente deve apresentar, a cada cinco anos de efetivo exercício, certificado de cursos na área de atuação, que totalizam carga horária de cento e oitenta horas-aula, a fim de progredir verticalmente na carreira. Os professores que declararam não participação em cursos de aperfeiçoamento nos últimos 10 anos, certamente, já atingiram a última etapa desta progressão, que pode ocorrer aos 21 anos de efetivo exercício. Assim, não necessitam mais destes certificados, para a respectiva finalidade.

${ }^{v i}$ A EAPE é um órgão do Distrito Federal vinculado à Secretaria de Educação do DF que gerencia a oferta de cursos de formação continuada aos professores da educação básica das escolas públicas.

vii Os professores em regime de contrato temporário são contratados para trabalhar por um período predeterminado, que pode se estender, ao máximo, por um ano consecutivo, podendo ser renovado por igual tempo. Eles não possuem estabilidade no emprego. 